\title{
Buffer Stock Operations and Well-Being: The Case of Smallholder Farmers in Ghana
}

\author{
Emmanuel Abokyi ${ }^{1,2} \mathbb{D} \cdot$ Dirk Strijker $^{3} \cdot$ Kofi Fred Asiedu ${ }^{4} \cdot$ Michiel N. Daams $^{2}$
}

Accepted: 7 April 2021 / Published online: 16 April 2021

(c) The Author(s) 2021

\begin{abstract}
This study investigates the possible causal relationship between buffer stock operations in Ghanaian agriculture and the well-being of smallholder farmers in a developing world setting. We analyze the differences in the objective and subjective well-being of smallholder farmers who do or do not participate in a buffer stock price stabilization policy initiative, using self-reported assessments of 507 farmers. We adopt a two-stage least square instrumental variable estimation to account for possible endogeneity. Our results provide evidence that participation in buffer stock operations improves the objective and subjective well-being of smallholder farmers by $20 \%$ and $15 \%$, respectively. Also, with estimated coefficient of 1.033, we find a significant and robust relationship between objective wellbeing and subjective well-being among smallholder farmers. This relationship implies that improving objective well-being enhances the subjective well-being of the farmers. We also find that the activities of intermediaries decrease both the objective and subjective well-being of farmers. This study demonstrates that economic, social, and environmental aspects of agricultural life could constitute priorities for public policy in improving wellbeing, given their strong correlation with the well-being of farmers. Based on the results of this study, we provide a better understanding, which may aid policy-makers, that public buffer stockholding operations policy is a viable tool for improving the well-being of smallholder farmers in a developing country.
\end{abstract}

Keywords Buffer stock operations · Objective well-being · Subjective well-being · Smallholder farmers $\cdot$ Instrumental variable $\cdot$ Ghana

\section{Introduction}

An agricultural policy that has drawn attention in sub-Saharan African countries in recent years is the buffer stock operations (BSO). Buffer stock operation is a governmental farm policy aimed at providing smallholder farmers in rural areas better access to the market to stabilize food prices. BSO is often implemented as a market intervention policy in a failed market environment, and it involves the buying and selling of agricultural commodity,

Emmanuel Abokyi

eabokyi@gimpa.edu.gh

Extended author information available on the last page of the article 
mostly grain, to guarantee that market prices only move within a price band by publicly announcing floor and ceiling prices to restrict price movement (Kornher \& Kalkuhl, 2013). Abokyi et al. (2020) observed that larger buffer stockholdings usually permit a longer period of stable prices, but at costs that rise exponentially over time, while smaller stocks imply that prices fluctuate more with substantial cost savings. The application of this type of initiative in most countries is to improve producers' incomes and well-being.

In the buffer stock operation system, as applied in Ghana, a dual pricing mechanism is used. This pricing mechanism involves setting up floor and ceiling prices (Abokyi et al., 2018). Products are bought at the floor price, and stocks are sold out at a ceiling price later in the year. The Government of Ghana introduced a buffer stock policy in 2010. The National Food Buffer Stock Company (NAFCO) is the leading implementer of the policy. Licensed buying agents (LBAs) purchase the cereals for NAFCO at the farm gate for the floor price, providing farmers access to efficient markets devoid of intermediaries' activities, thus also mitigating asymmetric information problems (see Abokyi et al., 2018).

However, despite the critical role of NAFCO in ensuring a market for produce such as maize, supporting the provision of stable income, and affording better nutrition of farmers' families, its effectiveness on the overall well-being of beneficiary farmers is not well documented. This probably hampers extension of the scheme to other crops like rice and sorghum, which also experience high price volatility, and the full participation of other farmers cultivating other crops. Some critics also argue that BSO do not help smallholder farmers since the margin between off-season and main-season prices is narrow (Alam et al., 2020). Additionally, it is reported that LBAs sometimes cheat farmers by offering prices lower than the NAFCO ones due to lack of information by farmers. There is evidence that not all farmers in the implementation areas participate in the initiative because of a lack of information and demonstrable improvement in participating farmers' well-being (Abokyi et al., 2020). Therefore, we examine the BSO policy after a decade of implementation and ask: what has been the impact of the policy on the overall well-being of smallholder farmers? To what extent is objective well-being (OWB) a good predictor for subjective wellbeing (SWB) of smallholder farmers, and what explains any differences?

There exists an extensive literature on well-being, its measurements, and determinants. For instance, well-being studies often measure happiness, its determinants and quantify the relative importance of factors affecting well-being (see Ballas \& Tranmer, 2012). There is no unified definition and measurement of well-being; however, it is generally accepted that well-being is a measure of the quality of life or progress of life (Rao \& Min, 2018). Most definitions conclude that well-being is multi-dimensional measure of the quality and progress of life (Haq \& Zia, 2013). Hence, improved well-being reflects the improved quality of life.

The concept of OWB mostly signifies physical conditions of living or aspects of wellbeing that, in principle, can be verified by an external observer. Hence it does take the subjective perspective of the'individual's judgment about his or her life into account (White, 2015). In contrast to OWB, subjective dimensions of well-being are those factors that take into account the perception and interpretation by the person himself or herself, that is, the thoughts and feelings of the individual where in principle, the individual is the authority in the assessment (Chindarkar et al., 2019). In other words, SWB provides a judgment of the well-being of the individual based on the individual's perception of satisfaction with life or overall happiness (Diener et al., 2010).

From a measurement perspective and as a multifaceted phenomenon, well-being can be assessed by measuring a wide array of objective and subjective indicators (Haq \& Zia, 2013). OWB most often uses socio-economic indicators to assess life quality to 
portray achievement or failure. The quality of life indicators for assessing OWB include material resources (e.g., food, income, housing), social attributes (e.g., education, community relationship, social networks and connections), personal attributes (e.g., health, mental status), environmental indicators (e.g., security, pollution, sanitation, access to basic amenities), among others (Ballas \& Tranmer, 2012; Western \& Tomaszewski, 2016). It is assumed that changes in these OWB indicators indicates one has acquired a better quality of life or not. At the household level, measuring OWB is to account for the household's basic needs and rights that should be required before its members can live well and flourish (Dolan et al., 2011; Hicks et al., 2013).

Generally, subjective well-being is measured by four indicators; the perceived level of overall happiness, satisfaction with life, thoughts about the future, and/or meaningfulness of life (Diener et al., 2010; Lopes et al., 2010). As an appraisal of'one's life, SWB is framed through cognitive and affective dimensions of life. While the cognitive dimension deals with the evaluation of life as a whole, the affective dimension deals with positive affects (e.g. happiness) and adverse effects (e.g. anxiety). A standard measure of SWB is to ask people the question, "taking all things together, how do you judge your life." The response to this, which measures SWB by an individual, is based on the'individual's standard relating to personal experiences, desires, ideals, and expectations. These standards, driven by biological traits and social constructions, are used as a compass to evaluate life vis-à-vis achievements of some objectives, needs, and fulfillment of specific ambitions (Brulé \& Maggino, 2017). Simply, the cognitive dimension of SWB is based on what one has and what one wants.

Governments and academics worldwide are now more focusing on targeting wellbeing improvements besides income increase in designing policies for improving the quality of life (Churchill \& Smyth, 2019). As a result, the impact of governmental policy on poor smallholder farmers' well-being (both objective and subjective) has become more important to researchers. Therefore, we focus on how buffer stock operations, as a governmental policy, impact farmers' well-being in a developing country setting.

In Ghana, a developing country, the agricultural and food system is characterized by frequent and high food price volatilities with glut periods and lean periods resulting in income fluctuations. Farmers are unable to sell their produce during harvest periods due to a lack of access to efficient markets resulting in low prices and unstable income. These uncertainties resulting from unstable income add to SWB. When prices of farm produce continue to fall, farmers are likely to choose alternative crops with higher expected economic value (e.g., cocoa or cashew), and in the long run, this could affect the supply of grain (Xie \& Wang, 2017). Income instability makes smallholder households more uncertain about their future, and so makes living in rural areas less attractive.

This paper contributes to the agricultural policy of buffer stock operations by presenting evidence of the policy's impact on beneficiary smallholder farmers' well-being in Ghana. The paper provides a robust empirical analysis of the link between agricultural policy (price stabilization), implemented via buffer stock operations, and objective and subjective well-being. Policy-makers are concerned with understanding the nexus between OWB on SWB as this can inform policies that enhance SWB (Lane, 2017).

The rest of the paper is structured as follows: Sect. 2 provides a link between wellbeing and price stabilization. Section 3 presents the methods and data. The empirical results are presented in Sect. 4, with Sect. 5 presenting the conclusions and policy implications. 


\section{The Link Between Buffer Stock Operations and Farmers' Well-Being}

We base our analysis on the relationship between participation in buffer stock operations and well-being on the economic theory of procedural utility, as proposed by Frey et al. (2004). The procedural utility relates to'people's tendency to value the processes that lead to various outcomes (Kaminitz, 2019). Thus, the theory espouses that people do not only value actual outcomes of economic activities but also the conditions and processes that lead to the achievement of these outcomes (Kaminitz, 2019). Researchers have used the theory to study the SWB of farmers in a couple of studies (see Markussen et al., 2018; Duc, 2009, among others). The summary of these studies indicates that the SWB of farmers, measured as happiness, could relate to relative and absolute incomes and other objective indicators of life (see, for example, Markussen et al., 2018; Tsou \& Liu, 2001). Studies of SWB and agriculture in western countries have reported that farmers have higher life satisfaction than wage labor due to high procedural utility from self-employment in agriculture (Markussen 2018). Farmers' lifestyle of freedom and independence, working with animals, allows them to handle and resist work-related stress, improving their well-being (Melberg, 2003). However, for poor smallholder farmers, SWB due to self-employment is less documented (see Tran et al., 2018).

Smallholder farmers in many developing countries and also in Ghana lack the bargaining power to negotiate fair prices for their products and depend on intermediaries to sell their produce, reducing their self-independence in the market. These intermediaries or middlemen often exploit the farmers, reducing their freedom (Abu et al., 2016). The activities of NAFCO are expected to reduce the power of middlemen. NAFCO aims to reduce the challenges of transporting produce from remote areas to market centers to reduce postharvest loss amid price fluctuations (Dedehouanou et al., 2013). Thus, by providing this service, buffer stock operation eventually stabilizes farmers' income (Devereux, 2016). The more stable income for farmers, in turn, could create the procedural utility of SWB. Therefore, the non-stressful environment created by participation in the NAFCO could affect the well-being of farmers directly and indirectly (Devereux, 2016).

Nevertheless, the income level and income certainty, which may not necessarily come from NAFCO, could also influence farmers' SWB. Going to the market center to sell produce, i.e., not participating in NAFCO, may also have positive impacts for farmers: for example, going to market to sell produce could be fun, through the encounter with market actors and other farmers. Thus, to make attribution to estimate the impact of NAFCO, comparing NAFCO farmers and non-NAFCO farmers in terms of their well-being level is relevant. Hence, constructing a valid counterfactual group for the later analysis of impact is essential to distill the impact of NAFCO.

Conceptually, we postulate a direct relationship between participation in NAFCO and OWB and an indirect relationship between NAFCO and SWB. We reason that NAFCO is primarily designed to influence objective indicators, as is the case for most agricultural public policies. However, studies have shown that indicators of (OWB) affect SWB (Kubiszewski et al., 2018). Thus, conceptually, NAFCO is expected to improve SWB through improvement in the indicators of OWB as well.

Buffer stock operations may stabilize or improve income; however, studies of SWB and happiness have found an increase in income may not necessarily improve SWB (Easterlin paradox). The Easterlin paradox suggests that those with higher incomes have average levels of happiness within a country at a given time, and as their incomes increase, it makes little or no difference to overall happiness levels (Rinks, 2020). 


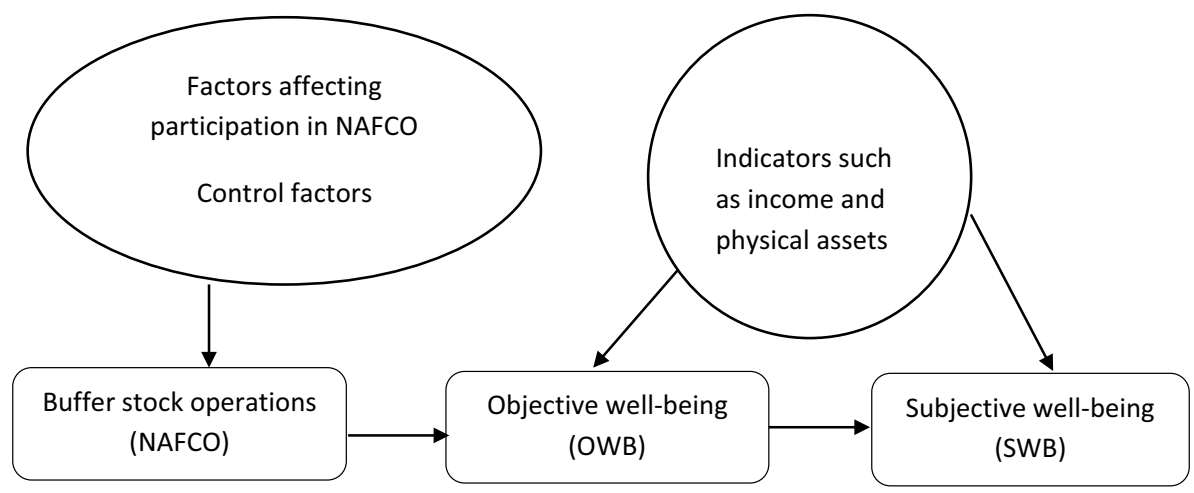

Fig. 1 The well-being-buffer stock operation framework. Note: Well-being $=f(z)$, where $z$ is a vector of variables including NAFCO; well-being is SWB or OWB

Thus, the effect of income on SWB is generally uncertain, and income directly relates to the SWB of poor people as it provides them with higher utility because, for poor people, income increase helps them avoid poverty (Diener \& Biswas-Diener, 2002). There are reported cases of increased income, having a positive association with SWB in low-income countries (Diener et al., 2010; Dluhosch et al., 2014). Income increases the SWB of the poor only insofar as it helps them meet their basic needs (Diener \& Biswas-Diener, 2002). Therefore, for poor smallholder farmers, increased income will most probably affect their SWB positively. Income stability has also been found to affect SWB (Devereux, 2016). Therefore, it follows that the agriculture policy (buffer stock operations), which stabilizes income, can theoretically and empirically affect OWB and SWB.

Empirical studies of the relationship between SWB and OWB have shown mixed results, with some reporting positive relationships, while others report no measurable effect. For instance, Jacob and Willits (1994) found that the relationships between SWB and OWB were small and inconsistent among Pennsylvania residents. They concluded that though the overall relationships between SWB and OWB were weak, they document strong linkages among different groupings within the population. Western and Tomaszewski (2016) reported a strong association between SWB and OWB among Australia's poor working class. Similar findings are reported in some middle-income countries such as Serbia (Vladisavljevic and Mentus, 2019).

In summary, the conceptual frame underpinning the work is presented in Fig. 1 below:

In the figure, NAFCO directly affects OWB through the factors that affect participating in the initiative, such as gender, education, and others. Over time, the improved OWB (if any), as an outcome of the NAFCO participation, subsequently affects the SWB of the farmers, subject to control factors enabling one to participate in NAFCO. The NAFCO-OWB-SWB relationship in Fig. 1 portrays improvement in SWB through the positive effects of NAFCO on OBW. Objective well-being can be measured at the group level, such as at the household level (Musa et al., 2018), to exemplify the quality of life that reflects the household situation and SWB at the individual-level, as a perception-based level, representing the views and feelings of the individual. 


\section{Materials and Methods}

\subsection{Measures of Well-Being}

We estimate the impact of buffer stock operations on smallholder'farmer' OWB by selecting 12 indicators related to 3 domains of life: economic, social, and environment (Alatartseva \& Barysheva, 2015; Musa et al., 2018; Western \& Tomaszewski, 2016). The motivation for these indicators is to enable us to capture the aspects of life-related to the basic needs of poor smallholder farmers. These basic needs include, but are not limited to, nutrition, housing, healthcare, and human dignity/psychological needs (Dolan et al., 2011; Hicks et al., 2013).

For the economic domain, we look at the financial situation (income), farming work (job), food security, and the marketing of farm produces (Dedehouanou et al., 2013). The social dimension indicators include the relationship with community members, community work or communal labor activities, marriage, and health conditions (Musa et al., 2018; Ngamaba \& Soni, 2018; Stack \& Eshleman, 1998). These social indicators are behavioral variables that enhance socializing with friends and other community members (Ngamaba \& Soni, 2018; Kaliterna-Lipovčan and Prizmić-Larsen, 2016).

The indicators for the environmental domain, which have been used by various studies to measure well-being, with modifications to fit some context (see Musa et al., 2018; Tsou $\&$ Liu, 2001), are housing conditions, sanitation, personal and household'members' security, and access to basic amenities (Welsch \& Kühling, 2009). Though these 12 indicators are not exhaustive, they cover various aspects of the objective well-being of rural smallholder farmers' and capture their basic needs for measuring their objective well-being (see Appendix Table 6 for a summary of the indicators).

To obtain the variables, we developed an instrument to elicit information on aspects of'households' OWB. Answers to a set of questions relating to the 12 indicators, on a scale ranging from 1 to 10 , where 1 is the worst condition observed, and 10 is the best condition, was used (see Mahasuweerachai \& Pangjai, 2018). We used the responses relating to the 12 indicators to develop a composite index for household-level OWB measure by following two steps commonly used to develop a composite index: weighting and aggregations (Musa, 2018; Mazziotta \& Pareto, 2013). We weighted all the indicators equally, then summed all the scores for the responses of the 12 indicators and divided the aggregate numbers by 12 to obtain the OWB index for each household. We apply equal weights as, while each of the aspects of life measured by the indicators is important to the smallholders, data on the relative importance of the aspects of life among farmers is not available. Indeed, the literature suggests that in the absence of data on the relative importance of life aspects among smallholder farmers, equal weighting is appropriate (Noor et al., 2014). The linear aggregation's key advantage is its simplicity and ease to construct and interpret (Mazziotta \& Pareto, 2013).

For SWB measurement, literature depicts three aspects of SWB: hedonic, evaluative, and eudemonic (see Chindarkar et al., 2019). They describe hedonic aspects as the experiences of positive and negative emotions such as smiles, pain, happiness, anxiety, or pleasure, demonstrated by the experienced utility and is typically focused on short periods. Evaluative well-being refers to the overall evaluation of'one's life and is stable over time, and eudemonic depicts'one's self-realization and meaning of life. Because evaluative SWB is a global evaluation of'one's life and is relatively stable over time, it represents a better metric of SWB to measure for the NAFCO effect after a decade of implementation 
(Chindarkar et al., 2019). Thus, we follow Zweig (2015) to measure evaluative SWB based on the responses to the question:

"Please imagine a ladder with ten steps. Suppose the top of the ladder represents the best possible life for you, and the bottom of the ladder represents the worst possible life for you. On which step of the ladder would you say you feel you stand at this time, assuming that the higher the step, the better you feel about your life, and the lower the step, the worse you feel about your life now"?" To ensure the validity of the above metric to capture the individual's subjective well-being, we motivated the respondent to provide the response that reflects his/her life globally and not to focus on one particular aspect of life. The respondents were allowed to engage with the interviewer to understand the question. Furthermore, respondents were approached in their homes, assured of the confidentiality of the information and not to use their family names, and are free not to answer any question they do not want to answer.

\subsection{Control Variables}

Consistent with well-being literature, we collect household and demographic factors data that are likely to affect well-being, including age, marital status, education, and household size (Shui et al. 2020; Kuykendall \& Tay, 2015; Zweig, 2015). The covariates also include variables that consider the smallholder context, including engagement in non-farm activities, livestock production, access to market, and extension services. Because the sample covers different districts, there is a potential for district-level factors affecting well-being, especially SWB (Rijnks, 2020). As a further check, we need to identify and control for districts-level characteristics which are likely to affect a district's adoption of NAFCO. Hence to account for characteristics which possibly affect local adoption of NAFCO, we control for differences across communities using two variables: the extent of intermediaries' activities and the perceived level of relevance of maize to the local economy, as measured at the district-level. As an additional check, we also control for cocoa farming activities (a highincome activity). The description of the variables and their measurement are presented in Table 1.

\subsection{Estimation Strategy}

In order to estimate the effect of participation in the buffer stock operations on OWB, we estimate the following well-being equation:

$$
O B W_{i}=\delta_{0}+\pi_{1} N A F C O_{i}+\beta_{n} X_{i}+\chi_{n} T_{i}+\varepsilon_{i}
$$

where the variables are as defined in Table $1 X$ is a vector of individual-level control variables, namely gender, age, marital status, household size, engagement in livestock production; $T$ is a vector of context and district-level control variables, including engagement in secondary occupation, the extent of intermediaries' activities in the community/ nearby market, and the relevance of maize production to the local economy; $\varepsilon$ is the error term, $\delta_{0}$, and $\pi_{1}$ are parameters to be estimated. $\beta_{\mathrm{n}}$ and $\chi_{\mathrm{n}}$ are $(\mathrm{n} \times 1)$ vectors of parameters corresponding to each of the control variables in the $X i$ and $T_{i}$ vectors. To estimate Eq. (1), coarsened exact matching (CEM) and two-stage least square (2SLS) techniques are adopted. 


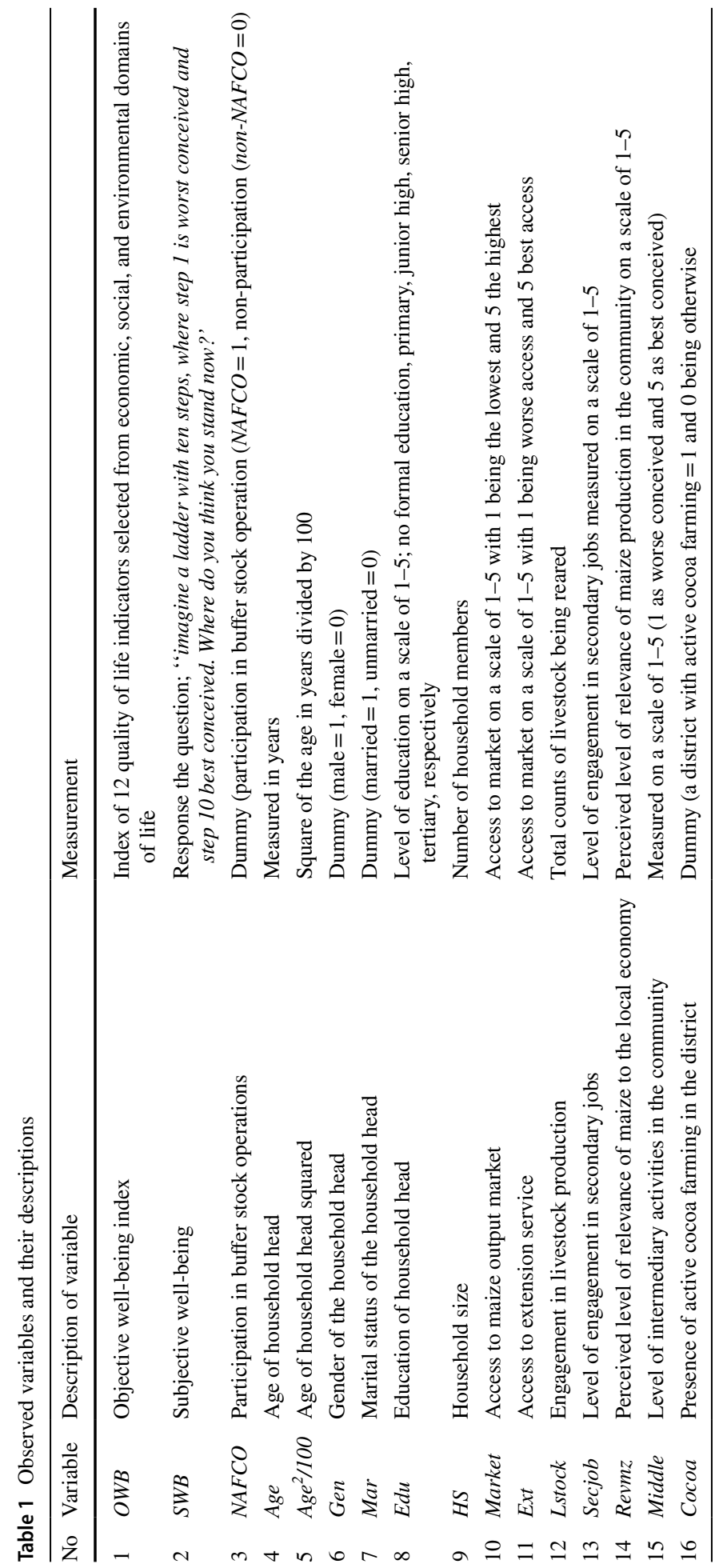


Before estimating Eq. (1), however, we further consider possible endogeneity, reflecting reverse causality between OWB and'farmer's participation in NAFCO. If present in the data, endogeneity may have three leading causes; self-selection bias, omitted variable(s), and measurement errors (Cawley, 2018). We address each of these possible issues by adopting a twofold approach. First, we use the coarsened exact matching (CEM) technique to address endogeneity due to selection bias (Iacus et al., 2012). Self-selection could bias the estimates, especially ordinary least square (OLS) estimates, and needs to be accounted for. CEM does so by generating a more balanced sample by ensuring the covariates of the treated and control groups have closely similar distributional characteristics, based on a matching approach (see details in Iacus et al., 2011). A benefit of using CEM is that it allows the treated and the control groups to be balanced ex-ante, before the regression analysis, rather than through an iterative process of ex-post balance checking as with propensity score matching (Iacus et al., 2011). Also, because the matching is done before the regression analysis, CEM reduces model dependence.

Second, we employ an instrumental variable-based two-stage least square (2SLS) estimation approach to mitigate the possible influence of measurement error or omitted variables on the CEM balanced data. In doing so, we estimate the impact of buffer stock operations on OWB. The instrumental variables and the determinants of NAFCO, such as gender, age, marital status, household size, are used to predict the value of NAFCO in the first-stage regression. The predicted value of NAFCO from the first stage regression is then used in a second-stage regression (Eq. 1 above) to estimate the effect of NAFCO on OWB (Cawley et al., 2018). This methodology allows for an appropriate estimation of causal relationships.

However, for the 2SLS approach to provide consistent estimates, the instrument used must correlate highly with farmer participation in NAFCO. That is, the instrument should only affect participation in NAFCO. The effect on well-being, in contrast, should be indirect. In other words, the effect of the instrument for NAFCO on the dependent variable OWB should be entirely mediated via its effect on the NAFCO treatment assignment. To this end, we used access to market and extension services as instruments for NAFCO. We use two variables instead of one because using many variables as instruments improves precision (see Hansen et al., 2008 for further discussions on instrumental variable use). Both variables influenced farmers' decisions to participate in the buffer stock operations but do not directly influence objective well-being.

Land market theory suggests that OBW does not vary with distance to the market, as differences in transport costs are compensated by land prices (Alonso, 1960). ${ }^{1}$ Moreover, in many African countries, smallholder farmers in practice may sell at the farmgate regardless of having access to the market; as a lack of bargaining power, collusion from middlemen, higher transaction costs, and market tolls motivate farmers to sell at the farmgate instead of a designated market center. Therefore, mere access to the market tend not to improve well-being of smallholder farmers directly. However, the distance to the market does influence participation in NAFCO due to less time spend to market produce as farmers save time for other productive activities. Also, stable price from NAFCO does influence farmers' participation in the initiative compare to more volatile prices in the open market. Access to extension services does not affect OWB directly, except indirectly through the adoption of acceptable agricultural practices. For instance, extension is a cognitive factor

\footnotetext{
1 In additions, soil conditions are similar across the areas.
} 
that may influence farmer's adoption of sustainable agricultural practices (Dessart et al. 2018). However, extension agents provide information on $N A F C O$ and its price which motivate farmers' participation in NAFCO.

In the case of $N A F C O$ as an instrument for predicting OWB, we mainly consider the activities of buyers, who travel to the farm gates and provides an opportunity to all farmers, whether far or near market location, to sell their produce. With prices offered by the middlemen very low and uncompetitive, $N A F C O$ serves to influence the produce's pricing in relation to what intermediaries offer. In this case, not transporting produce compensates for lower prices.

To evaluate the instruments' overall strength and validity, the Cragg and Donald statistic (1993) is used. Weak identification can be rejected if, as assessed with the Cragg-Donald Wald statistic. The Cragg-Donald Wald statistic is the minimum eigenvalue of the generalized $F$ statistic from the first-stage regression model, with a benchmark value of 10 .

After estimating the effect of $N A F C O$ on $\mathrm{OWB}$, we estimate the effect of OWB on SWB based on Eq. (2):

$$
S W B_{i}=\sigma_{0}+\lambda_{1} O W B_{i}+\alpha_{n} X_{i}+\rho_{n} T_{i}+\mu_{i}
$$

where SWB is subjective well-being measured on a scale of 1-10 (per the question in Table 2), and the other variables have their usual description and measurement and $\mu$ as the error term. Note that OWB is a predicted OWB based on 2SLS estimation. In addition, we test the performance of the 2SLS using the Sargan and Basmann tests for overidentifying restrictions. The null hypothesis in these tests is: the instruments are not correlated with the residuals from the main stage regression (Habibov 2012).

Furthermore, the same explanatory variables as in Eq. (1) are included in Eq. (2). This means that the predicted OWB variable's coefficient will reflect the effect of higher or lower OWB caused by NAFCO participation. The indicators of quality of life used for measuring OWB and NAFCO need not be in SWB Eq. (2) as the predicted value of OWB captures the effect of both the quality of life indicators and NAFCO. Hence, incorporating in the SWB Eq. (2) would mean double counting. Instead, this model considers that $N A F C O$ affects SWB indirectly via OWB. Therefore, the OWB effect $\left(\lambda_{1}\right)$ in Eq. (2) is the mediated NAFCO-effect through OWB on SWB.

\subsection{Data and Study Area}

To ensure the representativeness of the selected sampled out of the targeted smallholder maize farmers in the study area, we stick to Bartlet et al. (2001) rule of thumb for sample selection:

$$
N=\frac{S^{2}(x)(y)}{(E)^{2}}
$$

where $N$ denotes sample size, $x$ is the proportion of the maize farmers who sell maize to NAFCO (30\%), $y$ is the proportion of the maize farmers who do not sell maize to NAFCO (70\%), $S$ is the number of standard deviations for a chosen confidence interval level (1.96), and $E$ is the allowable margin of error (5\%). The application of the above formula yields a sample of 420 . However, to account for missing data and potential non-response, we increased the sample to 520 distributed among the NAFCO and the non-NAFCO farmers after the survey. 


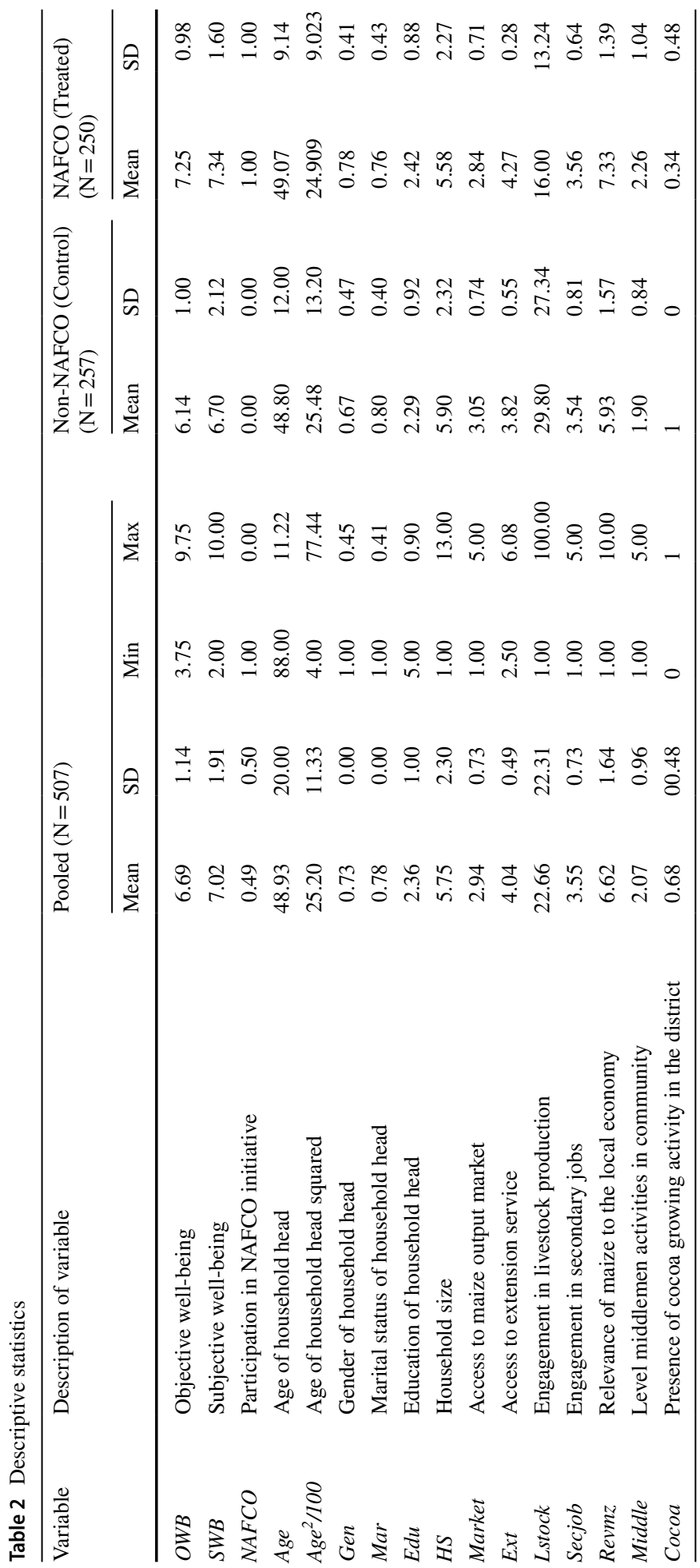


We developed a standardized questionnaire to collect household data from smallholder maize farmers. The survey was conducted in buffer stock operational area (policy-on) and policy-off area districts of Ghana. The choice of these districts was motivated by the districts being a maize production hub in the country. The districts located in the country's transition agroecological zone are Nkoranza South, Nkoranza North, Ejura Sekyere Kajebi, and Jasikan. Climatic and soil conditions in the study areas are optimal for maize production compared to other parts of the country, with smallholder farming being the dominant economic activity. The survey aimed to collect household data from NAFCO and non-NAFCO farmers to gather information on their quality of life indicators, SWB, and produce marketing. We surveyed between December 2017-January 2018, and three-stagestratified random is used to select farmers as follows: (1) district, (2) village, and (3) household. At the first stage, 3 districts were selected from the policy-on and 2 districts from the policy-off areas. We randomly selected 40 maize-growing villages out of the $90 \mathrm{com}$ munities across the observed districts at the second stage. A total of 40 communities were selected. The NAFCO policy-on areas had 18 villages, and the policy-off areas had 22 villages. At the third and final stage, households were randomly selected from each sampled village. Out of the 550 smallholder maize farmers contacted, 520 households completed the survey representing a response rate of $95 \%$. For those households that completed the survey, the policy-on/treated (NAFCO) farmers were 252 and the policy-off (non-NAFCO) farmers being 264. Information was elicited from the household head, assisted by his/her spouse, or next to a most senior member of the household in a face-to-face interview in the local Twi language.

The original questionnaire was written in English, and to ensure the exact meaning of the question we communicated, we translated the questionnaire into the Twi language. During the translation, it was essential to making sure that all the questions were worded to give the same meaning as the original ones. Also, we worded all questions the same way as they would be asked to minimize variations in information obtained from different enumerators. Before the field survey, we piloted the final instrument on 20 maize farmers in the Osudoku District. A review of the pilot test revealed no substantial change in meaning, ensuring the instrument's language validity. The pilot test's feedback also showed that each item in the instruments and the scale were understood by the respondents showing content validity. Descriptive statistics of the data are presented in Table 2.

From Table 2, men head most households; $67.9 \%$ and $78.0 \%$ for the BSO and non-BSO households, respectively. Generally, the average educational level, age, marital status, and household size are similar among the treated (NAFCO farmers) and the control groups (non-NAFCO farmers). Specifically, the pooled data with descriptive statistics of 2.42 show a low education level among farmers in Ghana for both groups. While the pooled data recorded an average of 6.69, the non-NAFCO farmers recorded 6.14, with the NAFCO farmers recording 7.25 for the OWB on a 10-point scale. The average SWB for the pool is 7.02 , with the non-NAFCO and NAFCO'farmers' households recording average values of 6.70 and 7.34 , respectively. 
Table 3 First-stage 2SLS regressions to obtain predicted values for NAFCO and OWB

\begin{tabular}{lll}
\hline Model (1) & & \\
\hline Variable & $\begin{array}{l}\text { Dependent variable: } \\
\text { NAFCO Coef }\end{array}$ & Dependent variable: OWB Coef \\
\hline Gen & $0.064(0.057)$ & $-0.101(0.118)$ \\
Age & $-0.044 * * *(0.011$ & $0.015(0.023)$ \\
Age & $1.235^{* * *}(0.251)$ & $-0.396(0.542)$ \\
Mar & $-0.036(0.060)$ & $0.093(0.126)$ \\
HS & $-0.028^{* * *}(0.010)$ & $0.057 * * *(0.021)$ \\
Education & $-0.047^{*}(0.025)$ & $0.011(0.053)$ \\
Lstock & $-0.004 * * *(0.001)$ & $0.003(0.002)$ \\
Lntscost & $0.159 * * *(0.053)$ & $0.039(0.113)$ \\
Secjob & $-0.191^{* * *}(0.034)$ & $-0.067(0.060)$ \\
Revmz & $0.090^{* * *}(0.013)$ & $0.417 * * *(0.029)$ \\
Middle & $0.020(0.021)$ & $-0.156 * * *(0.043)$ \\
Ext & $0.428^{* * *}(0.050)$ & $0.629(0.104)$ \\
Market & $-0.091^{* * *}(0.028)$ & $0.026(0.058)$ \\
NAFCO & - & $0.630^{* * *}(0.103)$ \\
Cons & $-8.551^{* * *}(1.410)$ & $5.941^{* * *}(3.096)$ \\
F-stat & $28.39 * * *$ & $35.00^{* * *}$ \\
$R^{2}$ & 0.532 & 0.610 \\
Adj. $R^{2}$ & 0.514 & 0.595 \\
RMSE & 0.347 & 0.7523 \\
No. obs & 342 & 338 \\
\hline
\end{tabular}

$* * *, * *$, and $*$ represent $1 \%, 5 \%$ and $10 \%$ significance levels, respectively. The standard errors are in parenthesis

\section{Results and Discussion}

\subsection{CEM Matching}

We first present the initial imbalance results and the CEM matching that show that a prematching multivariable imbalance $\left(\mathrm{L}_{1}\right)$ measure of 0.442 reduced to a post matching Li of 0.114 , indicating an improved balance in the data. Thus, CEM reduced the heterogeneity between the groups in the means and in the marginal and joint distributions of the entire matching variables (see Appendix Table 8 for details of the CEM matching results). This means that differences in the OWB and SWB between the NAFCO and the non-NAFCO farmers are likely due to their participation in the buffer stock operations. To assess whether differences in OWB or SWB between NAFCO and non-NAFCO participants are actually due to participation in buffer stock operations, we now turn to regression model results.

\subsection{The Impact of Buffer Stock Operations on Well-Being}

As a first step to the 2SLS analysis, we use the Durbin-Wu-Hausman (DWH) test for endogeneity to formally evaluate the hypothesis that OWB is exogenous. A Durbin 
Table 4 The impact of buffer stock operations on objective well-being (OWB). Dependent variable: OWB

\begin{tabular}{lll}
\hline Variables & Model $(2)$ & \\
\cline { 2 - 3 } & OLS & 2SLS \\
\hline NAFCO (Treatment) & $0.626^{* * *}(0.101)$ & $1.213^{* * *}(0.216)$ \\
Gender & $-0.091(0.118)$ & $-0.130(0.288)$ \\
Age & $0.016(0.022)$ & $0.046(0.070)$ \\
Age & $-0.408(0.529)$ & $-1.238^{* *}(0.616)$ \\
Mar & $0.121(0.124)$ & $0.114(0.0129)$ \\
HS & $0.057^{* * *}(0.021)$ & $0.073^{* * *}(0.022)$ \\
Edu & $0.009(0.052)$ & $0.023^{*}(0.665)$ \\
Lstock & $0.002(0.002)$ & $0.006^{* * *}(0.002)$ \\
Lntscost & $0.035(0.112)$ & $-0.084(0.122)$ \\
Secjob & $-0.060(0.060)$ & $-0.030(0.062)$ \\
Revmz & $0.417^{* * *}(0.029)$ & $0.348^{* * *}(0.037)$ \\
Middle & $-0.161^{* * *}$ & $-0.179^{* * *}(0.045)$ \\
Constant & $6.067^{* *}(3.044)$ & $11.337^{* * *}(0.3621)$ \\
F (Wald chi $\left.{ }^{2}\right)$ & $42.63^{* * *}$ & $473^{* * *}$ \\
$R^{2}$ & 0.614 & 0.567 \\
Adj. $R^{2}$ & 0.600 & - \\
RMSE & 0.722 & 0.745 \\
No. obs & 342 & 338 \\
\hline
\end{tabular}

$* * *, * *$, and $*$ represent $1 \%, 5 \%$ and $10 \%$ significance levels, respectively. The standard errors are in parenthesis

(score) $\mathrm{chi}^{2}$ of 11.010 and $\mathrm{Wu}-\mathrm{Hausman} \mathrm{F}$-statistic of 10.091 are significant at $1 \%$. The significant test statistic implies that the variable, OWB, is endogenous. Similarly, the regression-based endogeneity test (DWH) presented in Appendix Table 7 shows that the coefficients of -3.0325 and 4.049 of the residuals for the OWB and SWB, respectively, are both significant at $1 \%$. These results indicate the presence of endogeneity, justifying the use of the 2SLS estimation technique. The results of the first stage regression of the 2SLS estimation are presented in Table 3. The results in Table 3 present the regressions to obtain the predicted values of NAFCO and OWB for the subsequent (second state) estimation of the 2SLS estimation. Note that we included age squared $\left(\mathrm{Age}^{2}\right)$ in the objective well-being (OWB) and subjective well-being regression, as most empirical studies of subjective well-being find $\mathrm{Age}^{2}$ as a determinant (Blanchflower \& Oswald, 2008; Senasu \& Singhapakdi, 2017). The community's satisfaction is also captured by safety living in the community and relationship with community members, which were used in indexing OBW.

The summary statistics of the first stage equation show Cragg and Donald Wald statistics (minimum eigenvalue) of 64.82 and 22.00 for the $N A F C O$ and OWB models, respectively, compared to the critical value of the Wald test of 19.93, which is significant at $10 \%$ leading us to reject the null hypothesis that the instruments are weak. Furthermore, the first-stage $F$-statistics for the regressions in Table 3 confirm the instruments' validity: the significant F-statistics values are greater than 10 (see Stock \& Yogo, 2005). In addition, the tests of overidentifying restrictions, the Sargan (2.34) and Basmann (2.28) statistics, are not significant at 10\% indicating the instruments are 
Table 5 The impact of buffer stock operations on subjective well-being (SWB). Dependent variable: SWB

\begin{tabular}{lll}
\hline Variable & Model (3) & \\
\cline { 2 - 3 } & OLS & 2SLS \\
\hline OWB & $0.987^{\mathrm{a}} * *(0.097)$ & $1.033^{* * *}(0.295)$ \\
Gen & $-0.408^{*}(0.218)$ & $-0.437^{* *}(0.215$ \\
Age & $0.069^{*}(0.040)$ & $0.070^{*}(0.040)$ \\
lnAge ${ }^{2}$ & $-1.599^{*}(0.940)$ & $-1.622^{*}(0.934)$ \\
Mar & $1.520^{* * *}(0.230)$ & $1.471^{* * *}(0.227)$ \\
Edu & $0.111(0.096)$ & $0.098(0.094)$ \\
HS & $0.077^{* *}(0.038)$ & $0.070^{*}(0.039)$ \\
Lstock & $0.007^{*}(0.004)$ & $0.008^{* *}(0.004)$ \\
Lntscost & $0.115(0.205)$ & $0.098(0.206)$ \\
Secjob & $0.325^{* *}(0.110)$ & $0.328^{* * *}(0.111)$ \\
Revmz & $-0.141^{* *}(0.068)$ & $-0.149(0.152)$ \\
Middle & $-0.286^{* * *}(0.079)$ & $-0.265^{* * *}(0.086)$ \\
Constant & $9.806^{*}(5.357)$ & $9.853^{* *}(5.242)$ \\
F $\left(\right.$ Wald chi $\left.{ }^{2}\right)$ & $24.31^{* * *}$ & $203.60^{* * *}$ \\
$R^{2}$ & 0.470 & 0.467 \\
Adj. $R^{2}$ & 0.451 & - \\
RMSE & 1.336 & 1.305 \\
No. obs & 342 & 338 \\
\hline
\end{tabular}

$* * *, * *$, and $*$ represent $1 \%, 5 \%$ and $10 \%$ significance levels, respectively. The standard errors are in parenthesis

${ }^{\mathrm{a}} \mathrm{OWB}$ in the $2 \mathrm{SLS}$ equations is OWB predicted based on the first stage regression presented in Table 3

not sufficiently related to well-being. As such, the Cragg and Donald Wald, Sargan, and Basmann tests further confirm that extension and market access are appropriately valid instruments for predicting $N A F C O$.

Tables 4 and 5 present the estimated models for the OWB and the SWB, respectively. the results for the OLS estimations are presented in addition to the 2SLS estimates for comparison (see Tables 4 and 5), although the OLS estimations are expected to produce bias and inconsistent estimates. Therefore, we restrict the rest of this discussion to the results for the 2SLS model. The overall goodness of fit statistics (Wald $\mathrm{Chi}^{2}$ and adjusted R-squared) for both the OWB and SWB for the 2SLS models in Tables 4 and 5 show a good fit.

In discussing the results, we first start with the NAFCO-effect on objective wellbeing (OWB) and then turn to the mediated NAFCO effect on subjective well-being (SWB). For model 2, it should be noted that though Lstock, and Middle are not significant in the OLS estimation, after accounting for possible endogeneity, the variables became significant, and the magnitudes of their coefficients increased. The magnitude of the coefficient of Lstock, for instance, increased from 0.002 to 0.006 and became significant at $1 \%$. Similarly, the NAFCO variable's coefficient in the OLS estimate increased from 0.626 to 1.213 in the 2SLS estimate, showing a downward bias of the OLS estimates presented in Table 4, as expected a priori based on initial tests (see Appendix A2). 
The 2SLS estimates in Table 4 show that the coefficient of NAFCO is 1.213 and significant at $1 \%$, indicating a positive impact of the $N A F C O$ initiative on the OWB of smallholder farmers. To compute how much of OWB the NAFCO farmers had more than the non-NAFCO farmers in percentage terms, we compare the treatment coefficient (ATT) to the mean objective well-being level (OWB), 6.14, (see Table 2) of the non-NAFCO farmers, we see that the OWB of NAFCO farmers is about $20 \%^{2}$ more than the non-NAFCO farmers. In other words, participation in NAFCO improves OWB by $20 \%$.

The 2SLS estimates in Table 4 further show that the control variables $H S, E d u$, and Lstock, all have a positive and significant association with OWB, providing further assurance that these variables are appropriate as control variables. Interestingly, the positive and significant coefficient of Lstock, 0.006, indicates that livestock production affects OWB positively. A possible explanation for this finding may be that income from livestock sales and improved access to protein from livestock meat enhances the food and nutrition security of farmers (Smith et al., 2013), bolstering their wealth and eventually well-being. The 2SLS model in Table 4 also shows that $\mathrm{Age}^{2}$ significant at $5 \%$ indicating that households with younger heads and older ones have a better OWB compared to middle age ones. The district-level control variables, Middle and Revmz, are highly significant as shown in Table 4 indicting the extent of intermediaries' activities and the perceived level of relevance of maize to the district economy are appropriate as control variables. ${ }^{3}$

Table 5 presents the results of modeling the relationship between SWB and OWB. Comparing the OLS and the 2SLS estimates show that both estimates are similar to those of the 2SLS, with the OLS results being biased downwards. The 2SLS estimates results show that the OWB estimated coefficient of 1.033 is significant at $1 \%$, indicating a strong association between OWB and SWB. The results mean that NAFCO has a mediating and indirect effect on SWB through OBW. This corroborates Western and Tomaszewski (2016) findings, who reported a strong association between SWB and OWB among the disadvantaged working class in Australia. They note that improvement in the OWB of households is critical for improvement in the SWB. Importantly, comparing the coefficient of OWB, 1.033, to the mean assessed SWB levels of the non-NAFCO farmers (6.70) in Table 2, the results indicate that the SWB of NAFCO farmers is about $15 \%{ }^{4}$ more than the non-NAFCO farmers. Hence, overall, our results support Tsai's (2009) general findings that price stabilization influences SWB. In the case of the observed smallholder farmers, price stabilization through buffer stock initiative improves SWB indirectly through the improvement of OWB.

In Table 5, we note a negative coefficient for gender, suggesting that women-headed households are more likely to be satisfied with life than men-headed ones, a finding consistent with Zweig (2015). Even though women, compared to men, are more likely to have lower incomes, less educated, and these inequalities could cause women to have lower SWB compared to men, this is not always the case. Research has shown that'women's aspirations in life are lower than'men's and are, therefore, easily satisfied with their life compared to men' (Clark, 1997). These aspirations are formed from culture and social norms,

\footnotetext{
2 The ATT divided by the OWB of the non-NAFCO farmers, i.e. 1.213/6.14.

3 The additional district-level level control variable, cocoa, introduce to control for district level characteristics show that the results remain qualitatively the same with some marginal differences quantitatively when compared to the 2SLS results in Tables 4 and 5 (see Table 9 in Appendix for results) attesting to the validity of the main results in Tables 4 and 5. Thus, activities of intermediaries and the perceived level of relevance of maize to the local economy control for district-level characteristics.

4 The ATT divided by the SWB of the non-NAFCO farmers, i.e. 1.033/6.70.
} 
which play an essential role in individuals' well-being: a phenomenon real for women in Ghana (see, for example, Zweigh 2015; Plagnol \& Easterlin, 2008). The $A g e^{2}$ term, which captures the possibility of a non-linear relationship between the household's head's age and SWB, is negative and significant, implying that the relationship between age and SWB is U-shaped. This result means that SWB is more for young people, decreases with age to reach a minimum, and increases afterward in later life stages (Blanchflower \& Oswald, 2008). Similar findings are reported by Senasu and Singhapakdi (2017) for Thailand.

The estimated coefficient for marriage has a positive and significant effect on SWB, suggesting that married smallholder farmers are happier than their unmarried counterparts. The reason for this finding could be that marriage promotes better health by increasing the likelihood of couples helping each other (Stack \& Eshleman, 1998). Research also shows that marriage helps encourage spouses to follow a healthy diet and gives emotional support to each other to reduce stress and pressure. Besides, marriage pools two partners' resources together for household use, providing each other with income security (Asiedu \& Folmer, 2007).

The variable HS (household size) coefficient is positive and significant, implying that farmers with larger households have better SWB than those with smaller sizes. This result is in line with the finding of Shui et al. (2020), documenting a positive association between household size and SWB. Though larger poor households are expected to be constrained by the low resource endowment in providing for their basic needs, they are satisfied because of the love, care, and prestige of a large family.

The 2SLS estimates in Table 5 further show that the level of engagement in secondary jobs has a negative association with SWB. Kuykendall and Tay (2015) explain that engagement in multiple jobs increases the workload and stress levels, lowering the SWB of farmers. Juggling between multiple careers/roles has been linked to stress-related health outcomes such as blood pressure, among others (Sumra \& Schillaci, 2015). Similarly, the significant negative estimate of middle (-0.265), implies that the activities of intermediaries in the communities are detrimental to both OBW and SWB of farmers. We find intermediaries as rent-seekers who exploit poor farmers by offering lower prices for their produce.

\section{Conclusions and Policy Implications}

This paper empirically examined the impacts of buffer stock operations imitative (NAFCO) on the objective well-being and subjective well-being of rural and poor smallholder maize farmers in Ghana. Drawing on cross-sectional data from participants and non-participants of the NAFCO initiative, our results confirm that objective well-being (OWB) has a strong relationship with subjective well-being (SWB). We also find that intermediaries' activities decrease both the objective and subjective well-being of smallholder maize farmers. Importantly, our findings document approximately $20 \%$ higher objective well-being and $15 \%$ higher subjective well-being of NAFCO farmers compared to the non-NAFCO farmers, after controlling for relevant factors. The findings buttress our a priori suggestion that the NAFCO initiative will positively impact the objective well-being and subjective wellbeing of farmers who participate in the initiative.

The results have some important policy implications for countries applying buffer stock operations in agriculture, such as Ghana. Buffer stock operations (NAFCO) improve both the objective and subjective well-being of smallholder maize farmers, with the latter improving through the former's positive effects. The study has unveiled the critical role of 
NAFCO in improving the well-being of smallholder farmers for improved quality of life. Therefore, it may be useful to upscale the NAFCO initiatives across the country to other cereal crops, such as rice, to benefit more farmers. Our findings could also inform potential policies that mitigate the adverse effects of middlemen/'intermediaries' activities in the maize industry because middlemen make farmers more vulnerable and less happy, leading to potentially switching. A switch to tree crops, say, cashew or cocoa will negatively impact food production and food security in the country. This finding presents a basis for further research into the implications of a potential switch from maize to cocoa or cashew production for household and national food security. The current study could also be extended to cover other rural social infrastructure such as water and sanitation, communication and energy that affect smallholder farmers' well-being.

\section{Appendix}

See Tables 6, 7, 8 and 9.

Table 6 Domains of life and their indicators for indexing OWB

\begin{tabular}{|c|c|}
\hline Domain (aspects) of life & Indicator $^{1}$ \\
\hline \multirow[t]{4}{*}{ Economic } & Your household financial situation (income) ${ }^{\mathrm{a}, \mathrm{b}}$ \\
\hline & Your households farming work situation ${ }^{a}$ \\
\hline & Household's food security situation ${ }^{\mathrm{b}}$ \\
\hline & The marketing of your farm produces \\
\hline \multirow[t]{4}{*}{ Social } & Your relationship with community members ${ }^{\mathrm{a}}$ \\
\hline & $\begin{array}{l}\text { Household members involvement in community } \\
\text { work/communal labor activities }^{\mathrm{d}}\end{array}$ \\
\hline & Health conditions ${ }^{\mathrm{a}}$ \\
\hline & Marriage $^{\mathrm{i}}$ \\
\hline \multirow[t]{4}{*}{ Environmental } & Access to basic amenities such as water, transport \\
\hline & Safety of household members ${ }^{c}$ \\
\hline & Environmental conditions (pollution and sanitation) ${ }^{\mathrm{c}}$ \\
\hline & Housing conditions ${ }^{\mathrm{c}}$ \\
\hline
\end{tabular}

\footnotetext{
${ }^{1}$ The superscripts indicate the studies that discussed the indicators: $a$, for Western and Tomaszewski (2016); $b$, is Alatartseva and Barysheva (2015); $c$, for Musa et al (2018); $d$, for Kaliterna-Lipovčan and Prizmić-Larsen (2016)
} 
Table 7 Endogeneity Test. The OWB/SWB Regression with the residuals from $\mathrm{NAFCO/OWB}$ Regressions

\begin{tabular}{lll}
\hline Variable & $\begin{array}{l}\text { OWB } \\
\text { Coef }\end{array}$ & $\begin{array}{l}\text { CWB } \\
\text { Coef }\end{array}$ \\
\hline OWB & - & $1.020^{* * *}(0.095)$ \\
NAFCO & $0.380^{* * *}(0.094)$ & $-1.234^{* * *}(0.246)$ \\
Gen & $0.473^{* * *}(0.146)$ & $-0.246(0.154)$ \\
Age & $-0.124^{* * *}(0.046)$ & $-0.058(0.039)$ \\
Age & $3.332^{* * *}(1.161)$ & $1.061(0.904)$ \\
HS & $-0.053(0.034)$ & $-0.125^{* * *}(0.042)$ \\
Edu & $-0.018(0.041)$ & $-0.005(0.079)$ \\
Lstock & $-0.009^{* *}(0.004)$ & $0.001(0.003)$ \\
Lntscost & $0.623^{* * *}(0.181)$ & $-0.262(0.185)$ \\
Secjob & $-0.944 * * *(0.224)$ & $0.949 * * *(0.184)$ \\
Revmz & $0.686^{* * *}(0.084)$ & $-1.730^{* * *}(0.255)$ \\
Middle & $0.041(0.061)$ & $0.158(0.103)$ \\
Ext & $2.062^{* * *}(0.493)$ & $-2.706^{* * *}(0.337)$ \\
Market & $-0.148^{* *}(0.073)$ & $-0.209^{* *}(0.098)$ \\
Residual & $-3.325^{* * *}(0.997)$ & $4.049 * * *(0.607)$ \\
Cons & $-22.830^{* * *}(8.233)$ & $-10.492^{*}(0.5 .504)$ \\
F & $50.89^{* * *}$ & $28.98^{* * *}$ \\
$R^{2}$ & 0.621 & 0.467 \\
Adj. $R^{2}$ & 0.610 & 0.448 \\
RMSE & 0.693 & 1.386 \\
No. obs & 450 & 450 \\
\hline & &
\end{tabular}




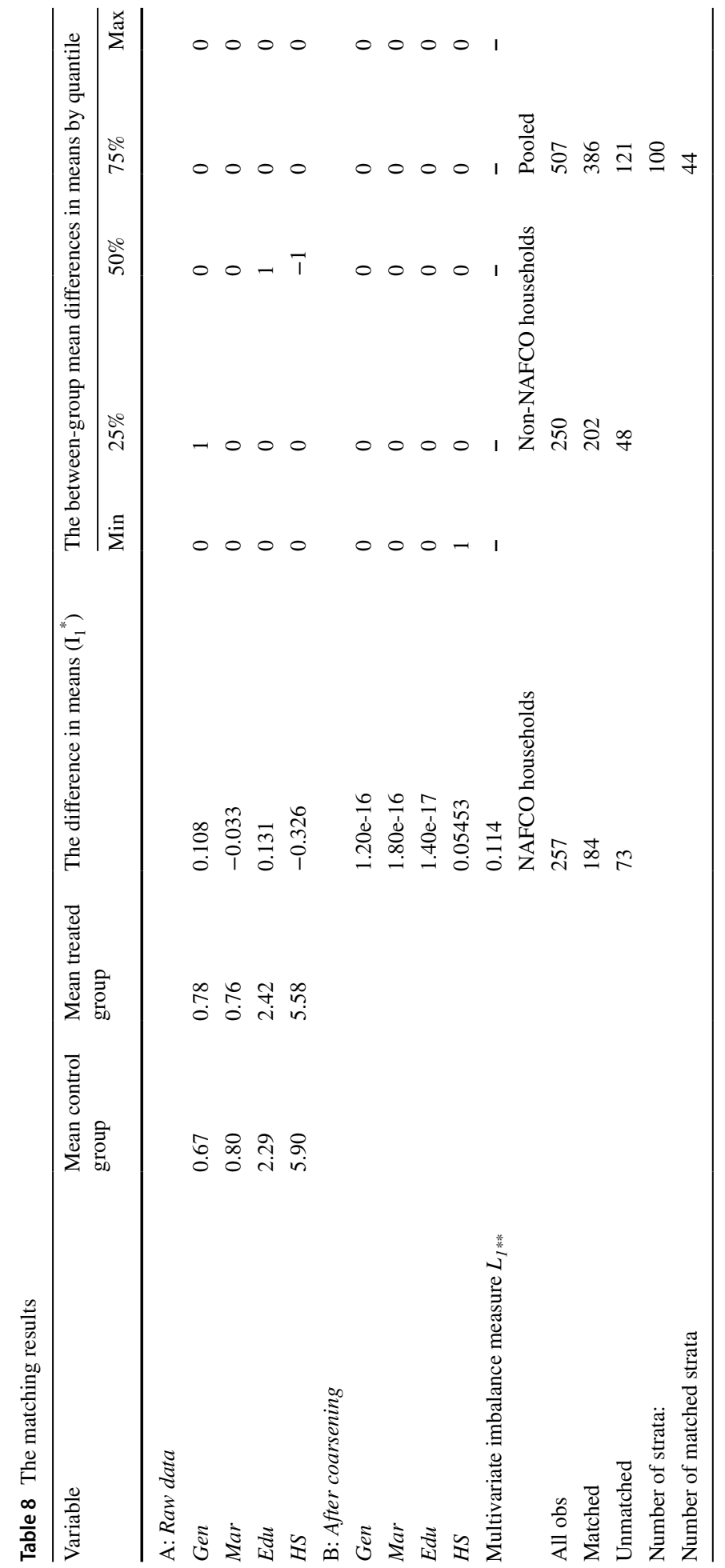


Table 9 2SLS results with additional district level control variable (cocoa)

\begin{tabular}{|c|c|c|}
\hline \multirow[t]{2}{*}{ Variable } & \multicolumn{2}{|l|}{ 2SLS } \\
\hline & OWB & SWB \\
\hline$N A F C O(O W B)$ & $1.387 * * *(0.295)$ & $0.809 * *(0.380)$ \\
\hline Gen & $-0.105(0.123)$ & $-0.465 * *(0.217)$ \\
\hline Age & $0.039(0.025)$ & $0.072 *(0.040)$ \\
\hline $\ln A g e^{2}$ & $-1.056^{*}(0.604)$ & $-1.699 *(0.942)$ \\
\hline Mar & $0.081(0.130)$ & $1.509 * * *(0.231)$ \\
\hline$E d u$ & $0.084 * * *(0.023)$ & $0.114(0.095)$ \\
\hline$H S$ & $0.006(0.055)$ & $0.083 * *(0.041)$ \\
\hline Lstock & $0.006^{* *}(0.002)$ & $0.008 * *(0.004)$ \\
\hline Lntscost & $-0.070(0.120)$ & $0.072(0.205)$ \\
\hline Secjob & $-0.016(0.065)$ & $-0.363^{* * *}(0.116)$ \\
\hline Revmz & $0.364 * * *(0.036)$ & $-0.057(0.183)$ \\
\hline Middle & $-0.195 * * *(0.046)$ & $-0.298 * * *(0.093)$ \\
\hline Cocoa & $0.383 * *(0.183)$ & $-0.216(0.215)$ \\
\hline Constant & $9.793 * * *(3.461)$ & $11.530 * *(5.519)$ \\
\hline$F\left(\right.$ Wald $\left.c h i^{2}\right)$ & $476.46 * * *$ & $208^{* *}$ \\
\hline$R^{2}$ & 0.563 & 0.465 \\
\hline$R M S E$ & 0.748 & 1.306 \\
\hline No. obs & 338 & 338 \\
\hline
\end{tabular}

Open Access This article is licensed under a Creative Commons Attribution 4.0 International License, which permits use, sharing, adaptation, distribution and reproduction in any medium or format, as long as you give appropriate credit to the original author(s) and the source, provide a link to the Creative Commons licence, and indicate if changes were made. The images or other third party material in this article are included in the article's Creative Commons licence, unless indicated otherwise in a credit line to the material. If material is not included in the article's Creative Commons licence and your intended use is not permitted by statutory regulation or exceeds the permitted use, you will need to obtain permission directly from the copyright holder. To view a copy of this licence, visit http://creativecommons.org/licenses/by/4.0/.

\section{References}

Abokyi, E., Folmer, H., \& Asiedu, K. F. (2018). Public buffer stocks as agricultural output price stabilization policy in Ghana. Agriculture \& Food Security, 7(1), 69.

Abokyi, E., Strijker, D., Asiedu, K. F., \& Daams, M. N. (2020). The impact of output price support on smallholder farmers' income: Evidence from maize farmers in Ghana. Heliyon, 6(9), e05013.

Abu, B. M., Issahaku, H., \& Nkegbe, P. K. (2016). Farmgate versus market centre sales: A multi-crop approach. Agricultural and Food Economics, 4(1), 21.

Alam, M. J., Akter, S., Begum, I. A., \& Haque, M. M. (2021). Determinants of the farm-level stocks of rice and effectiveness of rice procurement program in Bangladesh. Journal of the Asia Pacific Economy, 26(1), 116-139.

Alatartseva, E., \& Barysheva, G. (2015). Well-being: Subjective and objective aspects. Procedia-Social and Behavioral Sciences, 166, 36-42.

Alonso, W. (1960). A theory of the urban land market. Papers in regional science, 6(1), 149-157.

Asiedu, K. F., \& Folmer, H. (2007). Does privatization improve job satisfaction? The case of Ghana World Development, 35(10), 1779-1795. 
Ballas, D., \& Tranmer, M. (2012). Happy people or happy places? A multilevel modeling approach to the analysis of happiness and well-being. International Regional Science Review, 35(1), 70-102.

Blanchflower, D. G., \& Oswald, A. J. (2008). Is well-being U-shaped over the life cycle? Social Science \& Medicine, 66(8), 1733-1749.

Brulé, G., \& Maggino, F. (2017). Towards more complexity in subjective well-being studies. In Metrics of subjective well-being: Limits and improvements (pp. 1-17). Springer, Cham.

Cawley, A., ODonoghue, C., Heanue, K., Hilliard, R., \& Sheehan, M. (2018). The impact of extension services on farm-level income: An instrumental variable approach to combat endogeneity concerns. Applied Economic Perspectives and Policy, 40(4), 585-612

Chindarkar, N., Chen, Y. J., \& Gurung, Y. (2019). Subjective well-being effects of coping cost: Evidence from household water supply in Kathmandu Valley. Nepal. Journal of Happiness Studies, 20(8), 2581-2608.

Churchill, S. A., \& Smyth, R. (2019). Transport poverty and subjective well-being. Transportation Research Part A: Policy and practice, 124, 40-54.

Clark, A. E. (1997). Job satisfaction and gender: Why are women so happy at work? Labour Economics, 4(4), 341-372.

Cragg, J. G., \& Donald, S. G. (1993). 'Testing identifiability and specification in instrumental variable models.' Econometric Theory, 9, 222-240.

Dedehouanou, S. F., Swinnen, J., \& Maertens, M. (2013). Does contracting make farmers happy? Evidence from S enegal. Review of Income and Wealth, 59, S138-S160.

Dessart, F. J., Barreiro-Hurlé, J., \& van Bavel, R. (2019). Behavioural factors affecting the adoption of sustainable farming practices: a policy-oriented review. European Review of Agricultural Economics, $46(3), 417-471$.

Devereux, S. (2016). Social protection for enhanced food security in sub-Saharan Africa. Food Policy, 60, $52-62$.

Diener, E., \& Biswas-Diener, R. (2002). Will money increase subjective well-being? Social Indicators Research, 57(2), 119-169.

Diener, E., Ng, W., Harter, J., \& Arora, R. (2010). Wealth and happiness across the world: material prosperity predicts life evaluation, whereas psychosocial prosperity predicts positive feeling. Journal of Personality and Social Psychology, 99(1), 52.

Dluhosch, B., Horgos, D., \& Zimmermann, K. W. (2014). Social choice and social unemployment-income cleavages: New insights from happiness research. Journal of Happiness Studies, 15(6), 1513-1537.

Dolan, P., Layard, R., \& Metcalfe, R. (2011). Measuring subjective well-being for public policy (No. 35420). London School of Economics and Political Science, LSE Library.

Duc, N. M. (2009). Contribution of fish production to 'farmers' subjective well-being in Vietnam-A logistic model. Journal of the World Aquaculture Society, 40(3), 417-424.

Frey, B. S., Benz, M., \& Stutzer, A. (2004). Introducing procedural utility: Not only what, but also how matters. Journal of Institutional and Theoretical Economics, JITE, 160(3), 377-401.

Gasper, D. (2005). Subjective and objective well-being in relation to economic inputs: puzzles and responses. Review of Social Economy, 63(2), 177-206.

Habibov, N. (2015). On individual, household, and community factors explaining enrollment to early childhood education and care in post-Soviet transitional countries. Child Indicators Research, 8(4), $825-843$.

Hansen, C., Hausman, J., \& Newey, W. (2008). Estimation with many instrumental variables. Journal of Business \& Economic Statistics, 26(4), 398-422.

Haq, R., \& Zia, U. (2013). Multi-dimensional well-being: An index of quality of life in a developing economy. Social Indicators Research, 114(3), 997-1012.

Hicks, S., Tinkler, L., \& Allin, P. (2013). Measuring subjective well-being and its potential role in policy: Perspectives from the UK office for national statistics. Social Indicators Research, 114(1), 73-86.

Iacus, S. M., King, G., \& Porro, G. (2011). Multivariate matching methods that are monotonic imbalance bounding. Journal of the American Statistical Association, 106(493), 345-361.

Iacus, S. M., King, G., \& Porro, G. (2012). Causal inference without balance checking: Coarsened exact matching. Political Analysis, 20(1), 1-24.

Jacob, S. G., \& Willits, F. K. (1994). Objective and subjective indicators of community evaluation: A Pennsylvania assessment. Social Indicators Research, 32(2), 161-177.

Kaliterna-Lipovčan, L., \& Prizmić-Larsen, Z. (2016). What differs between happy and unhappy people? Springerplus, 5(1), 225.

Kalyuzhnova, Y., \& Kambhampati, U. (2008). The determinants of individual happiness in Kazakhstan. Economic Systems, 32(3), 285-299. 
Kaminitz, S. C. (2019). Contemporary procedural utility and 'Hume's early idea of utility. Journal of Happiness Studies, 20(1), 269-282.

Kornher, L., \& Kalkuhl, M. (2013). Food price volatility in developing countries and its determinants. Quarterly Journal of International Agriculture, 52(4), 277-308.

Kotrlik, J. W. K. J. W., \& Higgins, C. C. H. C. C. (2001). Organizational research: Determining appropriate sample size in survey research appropriate sample size in survey research. Information technology, learning, and performance journal, 19(1), 43.

Kuykendall, L., \& Tay, L. (2015). Employee subjective well-being and physiological functioning: An integrative model. Health psychology open, 2(1), 2055102915592090.

Lane, T. (2017). How does happiness relate to economic behaviour? A review of the literature. Journal of behavioral and experimental economics, 68, 62-78.

Lopes, M., Palma, P., \& Cunha, M. (2010). Tolerance is not enough: The moderating role of optimism on perceptions of regional economic performance. Social Indicators Research, 102(2), 333-350.

Mahasuweerachai, P., \& Pangjai, S. (2018). Does piped water improve happiness? A case from Asian rural communities. Journal of Happiness Studies, 19(5), 1329-1346.

Markussen, T., Fibæk, M., Tarp, F., \& Tuan, N. D. A. (2018). The happy farmer: Self-employment and subjective well-being in rural Vietnam. Journal of Happiness Studies, 19(6), 1613-1636.

Mazziotta, M., \& Pareto, A. (2013). A non-compensatory composite index for measuring well-being over time. Cogito. Multidisciplinary Research Journal, 5(4), 93-104.

Melberg, K. (2003). Farming, stress and psychological well-being: The case of Norwegian farm spouses. Sociologia Ruralis, 43(1), 56-76.

Musa, H. D., Yacob, M. R., Abdullah, A. M., \& Ishak, M. Y. (2018). 'Enhancing subjective well-being through strategic urban planning: Development and application of community happiness 'index. Sustainable Cities and Society, 38, 184-194.

Ngamaba, K. H., \& Soni, D. (2018). Are happiness and life satisfaction different across religious groups? exploring determinants of happiness and life satisfaction. Journal of Religion and Health, 57(6), 2118-2139.

Noor, N. M., Gandhi, A. D., Ishak, I., \& Wok, S. (2014). Development of indicators for family well-being in Malaysia. Social indicators research, 115(1), 279-318.

Plagnol, A. C., \& Easterlin, R. (2008). Aspirations, attainments, and satisfaction: Life cycle differences between American women and men. Journal of Happiness Studies, 9(4), 601-619.

Rao, N. D., \& Min, J. (2018). Decent living standards: material prerequisites for human well-being. Social indicators research, 138(1), 225-244.

Rijnks, R. (2020). Subjective Well-Being in a Spatial Context. University of Groningen. https://doi. org/https://doi.org/10.33612/diss.133465113

Senasu, K., \& Singhapakdi, A. (2017). Determinants of happiness in Thailand: The moderating role of religiousness. Journal of Human Behavior in the Social Environment, 27(4), 270-290.

Smith, J., Sones, K., Grace, D., MacMillan, S., Tarawali, S., \& Herrero, M. (2013). Beyond milk, meat, and eggs: Role of livestock in food and nutrition security. Animal Frontiers, 3(1), 6-13.

Stack, S., \& Eshleman, J. R. (1998). 'Marital status and happiness: A 17-nation' study. Journal of Marriage and the Family, 60, 527-536.

Stock, J. H., \& Yogo, M. (2005). Testing for weak instruments in linear IV regression. In D. W. K. Andrews \& J. H. Stock (Eds.), Identification and inference for econometric models: Essays in Honor of Thomas Rothenberg. (pp. 80-108). Cambridge University Press.

Sumra, M. K., \& Schillaci, M. A. (2015). Stress and the multiple-role woman: Taking a closer look at the Superwoman. PLoS ONE, 10(3), e0120952.

Tran, T. Q., Nguyen, C. V., \& VanVu, H. (2018). Does economic inequality affect the quality of life of older people in rural Vietnam? Journal of Happiness Studies, 19(3), 781-799.

Tsai, M. C. (2009). Market openness, transition economies and subjective well-being. Journal of Happiness Studies, 10(5), 523-539.

Tsou, M. W., \& Liu, J. T. (2001). Happiness and domain satisfaction in Taiwan. Journal of Happiness Studies, 2, 269-288.

Vladisavljević, M., \& Mentus, V. (2019). The Structure of subjective well-being and its relation to objective well-being indicators: Evidence from EU-SILC for Serbia. Psychological reports, 122(1), 36-60.

Welsch, H., \& Kühling, J. (2009). Using happiness data for environmental valuation: Issues and applications. Journal of Economic Surveys, 23(2), 385-406.

Western, M., \& Tomaszewski, W. (2016). Subjective wellbeing, objective wellbeing and inequality in Australia. PLoS ONE, 11(10), e0163345.

White, S. (2015). Introduction. The many faces of well-being. In Cultures of Well-being: Method, Place, Policy (pp. 1-44). Palgrave Macmillan. 
Xie, H., \& Wang, B. (2017). An empirical analysis of the impact of agricultural product price fluctuations on 'China's grain yield. Sustainability, 9(6), 906.

Zweig, J. S. (2015). Are women happier than men? Evidence from the Gallup World Poll. Journal of Happiness Studies, 16(2), 515-541.

Publisher's Note Springer Nature remains neutral with regard to jurisdictional claims in published maps and institutional affiliations.

\section{Authors and Affiliations}

\section{Emmanuel Abokyi ${ }^{1,2}$ (D) Dirk Strijker ${ }^{3} \cdot$ Kofi Fred Asiedu ${ }^{4} \cdot$ Michiel N. Daams ${ }^{2}$}

Dirk Strijker

d.stijker@rug.nl

Kofi Fred Asiedu

fkasiedu@yahoo.com

Michiel N. Daams

m.n.daams@rug.nl

1 Ghana Institute of Management and Public Administration, P. O. B. AH 50, Accra, Ghana

2 Department of Economic Geography, Faculty of Spatial Sciences, University of Groningen, P. O. B. 800, 9700 AV Groningen, The Netherlands

3 Department of Cultural Geography, Faculty of Spatial Sciences, University of Groningen, P. O. B. 800, 9700 AV Groningen, The Netherlands

4 KAAF University College, Accra, Ghana 